\title{
Thermocamera studies of gases and vapours
}

\author{
P CARLSSON, B LJUNGQVIST, AND K NEIKTER \\ From the Department of Anaesthesia, Karolinska Hospital, and the Department of Heat Technology, \\ Royal Institute of Technology, Stockholm, Sweden
}

ABSTRACT Most gases and vapours with a bipolar molecular structure absorb infrared energy. If such a gas is interposed between an object emitting infrared radiation and a thermocamera the gas will absorb some of the infrared radiation and thus cast a shadow on the thermocamera picture. In this way it is possible to visualise the gas. This method had been used to study pollution with anaesthetic gases and vapours in operating theatres. The vapours of other chemicals used in hospitals and other places of work also have been studied. The method permits the study of dispersion and flow patterns of polluting gases and vapours during work.

Hitherto it has not been possible to study the dispersion and flow patterns of polluting gases and vapours invisible to the human eye. In this paper we show how the thermocamera technique can be applied to the study of the flow of gases and vapours under normal working conditions. We review two initial studies and also present the results of a study using an improved technique at a working place in an industrial working environment.

\section{Method}

The method that combines the law of energy absorption by gases with the principle of the thermocamera was described in 1979 by Allander and Ljungqvist. ${ }^{1}$

\section{ENERGY ABSORPTION BY GAS MOLECULES}

Most gas molecules containing one or more covalent bonds, resulting in a dipole moment in the molecular structure, will absorb infrared (IR) radiation. Each gas has a characteristic IR-absorption spectrum with a maximum absorption band. Exceptions are diatomic gases such as $\mathrm{H}_{2}, \mathrm{~N}_{2}$, and $\mathrm{O}_{2}$. Lambert-Beer states that: $\ln \frac{\mathbf{P}}{\mathbf{P}_{0}}=-\mathrm{k} 1 \mathrm{c}$ where $\frac{P}{P_{0}}$ is the transmission, $k$ the coefficient of extinction, 1 the length of the pathway, and $c$ the concentration of the gas, and expresses the relation-

Received 16 July 1981

Accepted 6 October 1981 ship between the absorbed energy and the concentration of the gas.

THERMOCAMERA TECHNIQUE

A body with a temperature higher than its surroundings will emit IR radiation. The amount of radiation emitted depends among other things on the difference in temperature; the greater the difference the more radiation emitted. Studies of thermal radiation (thermography) can be performed with a thermocamera. The camera consists of an IR detector measuring the IR radiation from a single point in the field of view. With the help of an optical-mechanical system the whole field of view is scanned and differences in IR radiation are measured.

Thus when an object emitting IR radiation is studied with the help of a thermocamera and a gas is interposed, the gas will cast a picture of extinction-seen as a shadow-on the picture sensed by the thermocamera. The absorption and emission of IR radiation by the atmosphere, especially by its content of water vapour, limits the practical use of the thermocamera to investigations in a short-wave region from 3.0 to $5.6 \mu \mathrm{m}$ and a longwave region from 8.0 to $14.0 \mu \mathrm{m}$.

EXPERIMENTAL SET-UP

An electrically heated screen measuring $1 \times 1$ metre is used as the source of IR radiation. To create high sensitivity and to avoid artefacts it is important to keep the temperature of the screen constant. In the two first investigations ${ }^{2} 3$ the temperature was about $60^{\circ} \mathrm{C}$ with variations in the range of $3-4^{\circ} \mathrm{C}$. The screen is placed $0.5-1.0 \mathrm{~m}$ behind the object or 


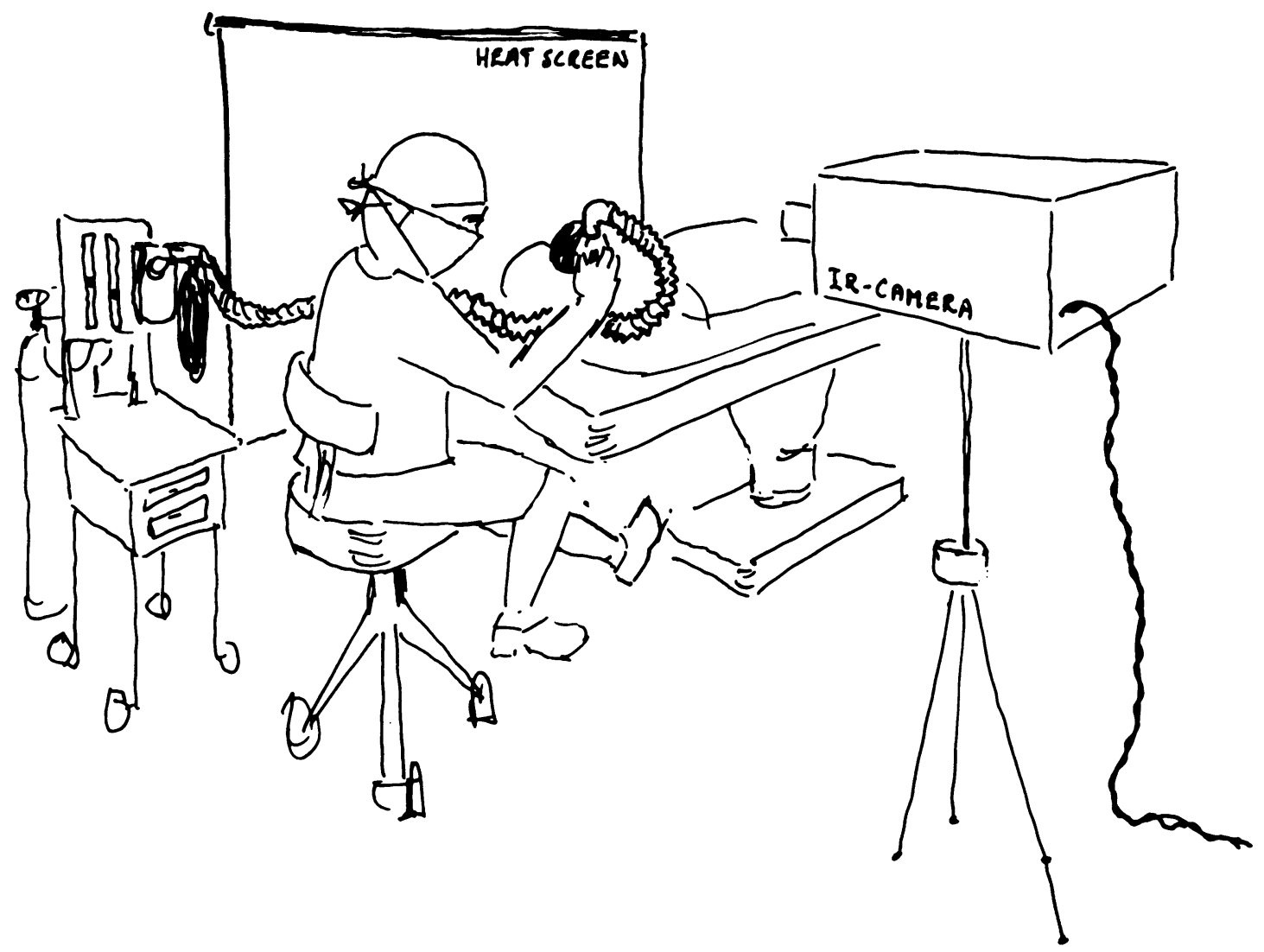

Fig 1 Experimental set-up. Anaesthetist and patient between heated screen and thermocamera. (Drawing B Hallén.)

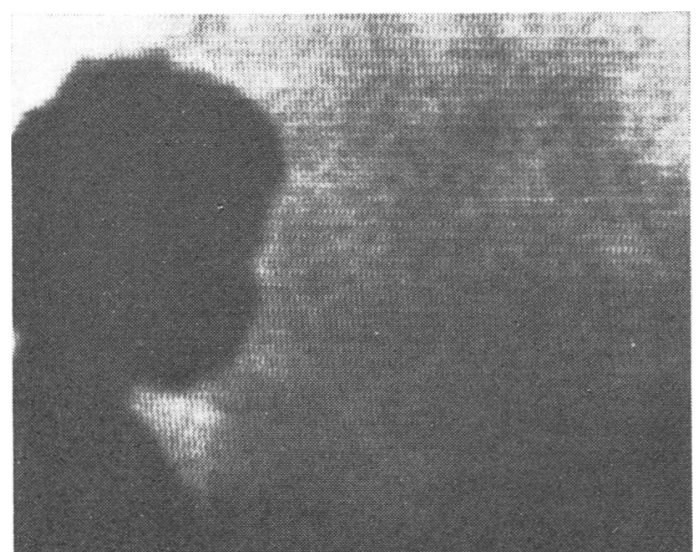

Fig 2 Infrared picture of fig 1. Nitrous oxide is leaking from face mask.

person to be investigated. A thermocamera (Aga Thermovision 780) is placed on the opposite side of the object at a distance of $1 \cdot 5-2 \mathrm{~m}$. The optical system of the camera is adjusted in such a way that the shadows of the area investigated are seen on the IR picture of the screen (fig 1).

The IR picture is presented on the monitor in shadows of grey (fig 2). As the amount of absorbed radiation is proportional to the total concentration of absorbing gas between the screen and the camera, the scale of grey represents the extinction and can, in many cases, be interpreted as a semiquantitative determination of the gas concentration; the higher the concentration the darker the shadow. As the depth of the cloud of gas is not exactly known, the IR picture cannot be used for exact measurements of concentration.

It is possible to convert the shades of grey stepwise into different colours and thus present the IR picture in colours, each colour corresponding to a certain range of extinction. The thermocamera picture may be photographed or filmed and the data stored for later use. 


\section{Results}

STUDIES OF GAS FLOW

The first study in a working environment was performed in the operating theatres at the Karolinska Hospital. ${ }^{2}$ The flow patterns of nitrous oxide leaking during anaesthetic procedures were investigated. Nitrous oxide is used either as the sole inhalation analgesic in combination with intravenous anaesthesia or as a vehicle for other inhalational anaesthetics. It is used in high concentrations, 50-70\% of a total flow of $4-101 / \mathrm{min}$. The maximum absorption of nitrous oxide is in the $4.5 \mu \mathrm{m}$ band. Therefore the short-wave region of the thermocamera was used and, to eliminate radiation outside a narrow band around $4.5 \mu \mathrm{m}$, a special optical filter was used. The nitrous oxide leaking from a poorly fitting face mask is seen around the head of the anaesthetist (fig 2). The nitrous oxide exhaled by the patients was detected five minutes after the end of the anaesthetic procedure. All activities during routine anaesthetic work that could lead to the contamination of the atmosphere of the operating room with nitrous oxide were studied and filmed. The material from this study has been edited into a film together with llustrations of how the same procedures may be performed in order to minimise contamination. This film has been used for education and discussions with anaesthetic personnel and students. The technique was also used to show the efficiency of close-scavenging equipment evacuating gases near the face mask, which is the most important source of contamination during mask anaesthesia.

The studies showed a recurring cause of a high degree of contamination-namely, lifting the face mask from the patient's face during mask anaesthesia. A valve automatically obstructing the flow out of the anaesthetic circuit during face mask lifts was constructed, and its efficiency could be immediately confirmed.

\section{SEMIQUANTITATIVE STUDIES}

To test the long-wave region of the thermocamera the vapours of two inhalation anaesthetic agents, enflurane $\left(\mathrm{CHF}_{2} \mathrm{OCClHCF}_{3}\right)$ and halothane $\left(\mathrm{CF}_{3} \mathrm{CHBrCl}\right)$, were studied. ${ }^{3}$ This study was performed without filters in the camera and took place in a room without general ventilation and thus without any major air currents to disturb the flow of the vapours. From an anaesthetic apparatus increasing concentrations of the agents were released into the room. The study confirmed and demonstrated an increasing absorption of IR radiation when the concentration of a vapour is increased.

Narrow peaks in the absorption spectrum of halothane and a lower molar absorbance of this agent predict a lighter shadow on the IR picture compared with the shadow from enflurane when the concentrations of the two agents are the same. This was also found, ${ }^{3}$ and thus this result confirms earlier reports ${ }^{4}$ of ambient concentrations found in proportion to the concentrations used. Thus, for routine surveillance of personnel exposure to hazardous gases, it seems sufficient to monitor one gas only when mixtures of gases or vapours, or both, are used in known concentrations.

\section{Present study}

Preliminary studies in the long-wave region were performed with other substances. Trichloroethylene, another inhalational anaesthetic agent widely used in the industry as a degreasing agent, and toluene were easily detected by the camera. Ethanol is used for disinfection in hospitals, and fig 3 shows its

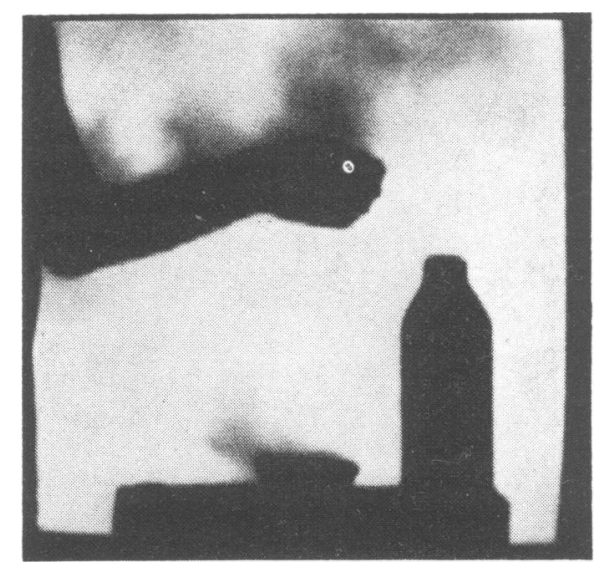

Fig 3 Ethanol evaporating from an arm after surgical scrub.

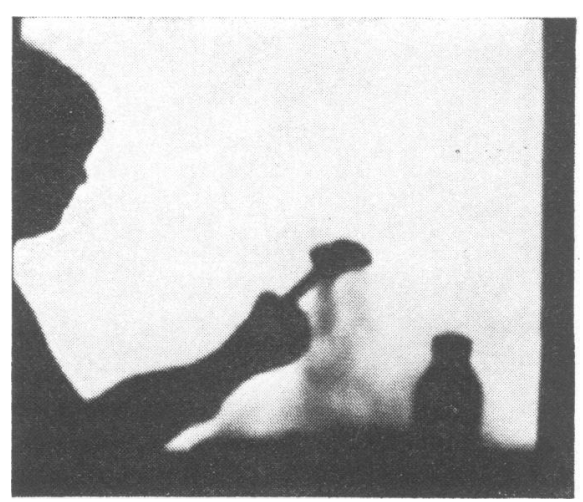

Fig 4 Diethylether evaporating from a surgical swab. 


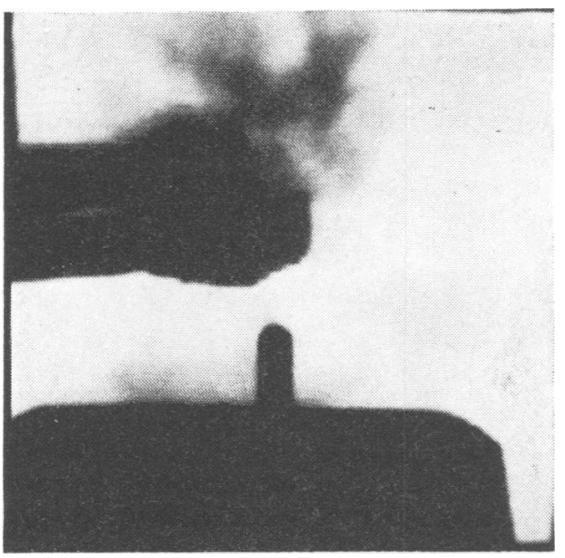

Fig 5 Preparation of methyl-methacrylate. Bowl is held up and stirred.

evaporation from the skin after a surgical scrub of an arm. The well-known anaesthetic diethylether also has a high molar absorbance and is easily studied (fig 4). Methyl-methacrylate, widely used in the plastics industry, is also used in hospitals for cementing joint prostheses. The cement is prepared immediately before use by mixing a powder of the plastic polymer with a liquid monomer. Figure 5 shows the vapours escaping during preparation.

In order to use fully the capacity of the thermocamera it was necessary to keep the surface of the screen at a more uniform temperature than could be achieved when heating the screen directly with electrical elements. A new screen was therefore constructed with a waterfilled chamber behind the front metal plate. The water is heated electrically and when circulated by means of a pump it secures an even distribution of heat to the front plate. To produce an even emission from the front plate it was painted with a coating originally used for light absorbing purposes but at the same time possessing a very high emittance factor, 0.94-0.96, in the wavelength range of 2.4 to $26.0 \mu \mathrm{m}$ (Nextel 2010 Velvet Coating Black, 3M). After these improvements the variations of the temperature of the screen can be kept within a range of $\pm 0.5^{\circ} \mathrm{C}$ at $65^{\circ} \mathrm{C}$.

The improved screen was used for a study at an industrial plant-SAS maintenance base for jet engines, Linta at Stockholm-Bromma Airport. The study was performed as part of the protection programme for the workers at the plant. We wanted to evalute improvements in ventilation at those places of work where engine parts are spray-painted or degreased. The following work processes were studied: spraypainting, cleaning of spray gun, and degreasing of engine parts with trichloroethylene.
SPRAY-PAINTING (figs 6, 7)

Some engine parts are sprayed with a dry lubricant (colloidal graphite and synthetic resin varnish) and an alcohol ester is used as thinner. To obtain an even distribution of the lubricant or paint the engine parts are slowly rotated on a turntable during the process. The ventilation of the working place is designed as a wind tunnel in order to remove the aerosol of paint and solvent quickly. The aerosol is caught by a "carpet" of falling water at the end of the tunnel.

\section{CLEANING THE SPRAY-GUN}

The spray-gun is cleaned by dipping it into and brushing it with a thinner. This is done close to a local exhaust ventilation system, but the camera showed that the evacuation at this site had little effect on the spread of thinner vapours (fig 8). This lack of effect of the evacuation system may be caused by an insufficient capacity of the system but it may also be explained by a wake region in front of the worker. These wakes are caused by the exhaust ventilation flow. They were visualised and studied by Ljungqvist $^{5}$ with smoke experiments, and we have also shown them with the thermocamera method.

\section{DEGREASING WITH TRICHLOROETHYLENE}

Before the engine is reassembled, many of the parts are cleaned and degreased in a basin containing vapours of trichloroethylene. The basin is $2 \times 2 \mathrm{~m}$ and $2 \mathrm{~m}$ high. Trichloroethylene is vaporised at the bottom of the basin and heated to $70^{\circ} \mathrm{C}$. The engine parts are hoisted into the basin. The size of the engine parts has necessitated a special design of the evacuation system in order to protect the workers. To prevent the vapours from escaping into the room, the upper part of the basin is cooled and the top of the basin is exhaust ventilated. Previous measurements of the TWA had shown a very low exposure to the operator of $6 \mathrm{ppm}$, and this was confirmed by the thermocamera study. No vapours were detected except when hoisting up the engine parts which released trichloroethylene vapours for a minute or two.

If the engine parts were kept in the evacuation zone a few minutes before being carried away no vapours could be detected by the thermocamera.

This study in the field confirms the possibilities of the thermocamera method and shows that it is possible to visualise the flow of vapours of hazardous agents while work is being performed under normal conditions. The results show that specially designed solutions to ventilation and evacuation problems are often more efficient than attempts to solve the problems with the "dilution-principle," using a high rate of general ventilation. 


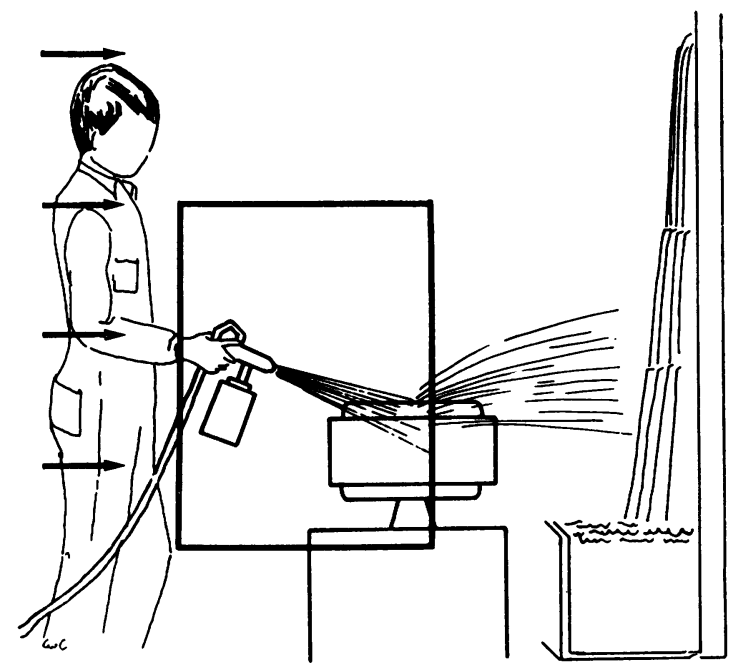

Fig 6 Spray-painting. Worker is spraying the engine part placed on a turntable. Arrows mark direction of air flow. Area investigated is marked with a frame.

\section{Discussion}

The different methods for estimating and studying distribution and flow patterns of anaesthetic gases and vapours in operating rooms may serve as examples of the difficulties encountered when examining the flow of invisible gases.

Whitcher et $a l^{6}$ measured the concentration of a contaminant (halothane) at nine points within a radius of 1 metre of the anaesthetic equipment and at three distant points. In this way the magnitude of the flow could be estimated, and by comparing the concentrations with and without evacuation of waste gases, the effect of scavenging at the exhaust valve of the anaesthetic system was shown. Thompson et al constructed an air movement vector pattern by measuring air speed and direction with a hotwire anemometer at more than 35 different sites in the operation room. These two methods require many measurements to give a good estimate of the flow. Otherwise the sampling method may introduce difficulties in the interpretation because of the rapid changes in air flow caused by vortices, currents, and wakes created by curtains and personnel.

Berner $^{8}$ substituted the anaesthetic gases with titanium tetrachloride smoke in order to study the directions of the air flow and dispersion of leaking anaesthetic gases. Ljungqvist ${ }^{5}$ used the same approach in his systematic studies of the dispersion of pollutants. The smoke method often offers a better and more easily understood visualisation of the air

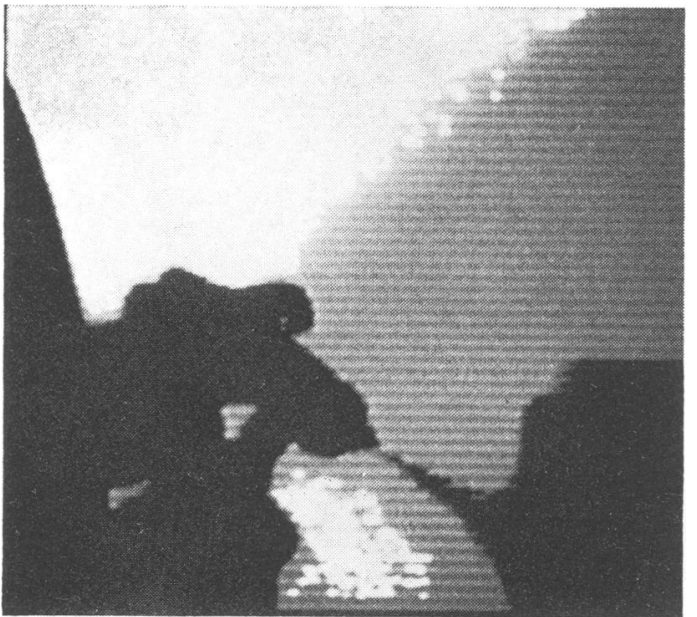

Fig 7 Infrared picture, as fig 6. Spread of paint is visualised.

flow than the previously mentioned methods. The smoke should have a temperature corresponding to that of the gas it substitutes. The room usually becomes filled with smoke quickly, an inconvenience that may prevent the use of smoke while work is is progress-for instance, in operating rooms.

Ljungqvist ${ }^{5}$ showed completely different patterns of dispersion between gases and particles released

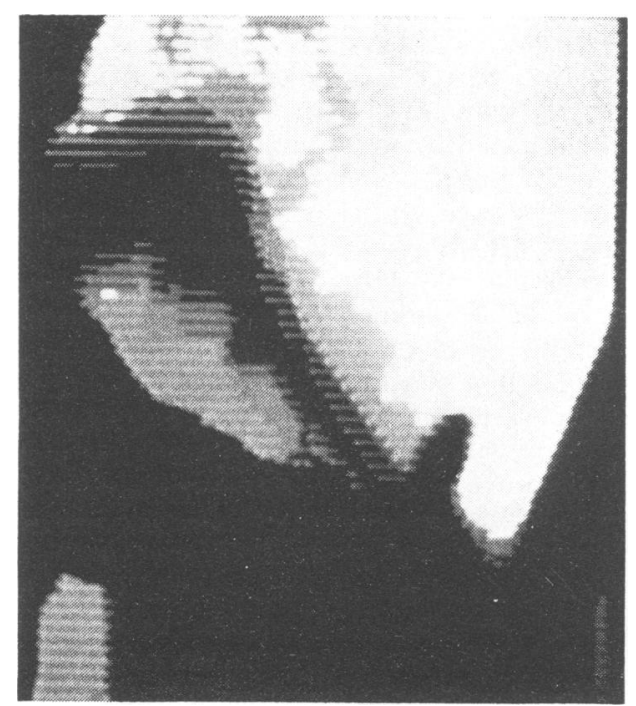

Fig 8 Worker brushing spray-gun with thinner. Vapours not evacuated despite evacuation system. 
under calm or laminar flow conditions. The smoke method therefore cannot be used to show the dispersion of gases under laminar flow conditions. As turbulence greatly increases diffusion the difference in dispersion will disappear under turbulent flow conditions. The dispersion of both gases and particles can therefore be visualised by the smoke method provided that turbulent conditions are established.

The thermocamera method visualises the flow of a contaminating gas under working conditions, and thus no error is introduced because of differences in density or other physical properties between the gas investigated and a smoke substitute. When comparing the flow of a continuously released, isothermic smoke and the spread of nitrous oxide found by the thermocamera investigation we did not find any major differences in the flow pattern when smoke and nitrous oxide were released under identical conditions. Thus the change in air flow introduced by the presence of the heated screen has no major influence on the results. The size of the screen will limit the area investigated to a maximum of $1 \mathrm{~m}^{2}$. On the other hand, this size was sufficient for the study of ambient atmosphere near personnel and apparatus in situations of interest.

With the use of filters it is possible to perform studies within a selected region of wavelengths, thus reducing interference from other gases present. This interference from other gases will depend on their molar absorbance and concentration in relation to those of the gas investigated. For instance, we did not find any interference from carbon dioxide when studying nitrous oxide, although the maxima of absorption of the two gases are found at almost the same wavelength. This was partly because of the filter used and partly because of the small concentration of carbon dioxide in relation to that of nitrous oxide. As more than one gas may absorb energy at specific wavelength and thus be seen in an IR picture it is not possible to distinguish between two or more gases found on the IR picture.

By visualising gases and vapours the thermocamera method shows the patterns of dispersion. The method is semiquantitative, so for exact measurements of concentrations conventional methods are superior and also cheaper. The thermocamera method, on the other hand, does enable continuous studies of the dispersion of polluting gases. Such studies are important as no other method has offered the possibility of visualising contaminating gases while work is in progress.

This study was supported by the Swedish Work Environment Fund, grants No 79/392 and 80/213.

\section{References}

${ }^{1}$ Allander C, Ljungqvist B. Air movements-the dispersion of pollution. Exploratory tests using the IR techniques. Document D16. Stockholm: Swedish Council for Building Research, 1979.

${ }^{2}$ Allander C, Carlsson P, Hallén B, Ljungqvist B, Norlander O. Thermocamera, a macroscopic method for the study of pollution with nitrous oxide in operating theatres. Acta Anaesthesiol Scand $1981 ; 25: 21-4$.

${ }^{3}$ Carlsson P, Ljungqvist B, Allander C, Hallén B, Norlander $O$. Thermocamera studies of enflurane and halothane. Acta Anaesthesiol Scand $1981 ; 25: 315-8$.

${ }^{4}$ Whitcher C, Piziali RG. Monitoring occupational exposure to inhalation anesthetics. Anesth Analg 1977;56:778-85.

${ }^{5}$ Ljungqvist B. Some observations on the interaction between air movements and the dispersion of pollution. Document D8. Stockholm: Swedish Council for Building Research, 1979. (Thesis.)

- Whitcher C, Cohen EN, Tondell J. Chronic exposure to anaesthetic gases in the operating room. Anesthesiology $1971 ; 35: 348-53$.

${ }^{7}$ Thompson JM, Barrat RS, Hutton P, Robinson JS, Belcher R, Stephen WI. Ambient air contamination in a dental outpatient theatre. Br J Anaesth 1979;51:845-54.

${ }^{8}$ Berner $O$. Concentration and elimination of anaesthetic gases in operating theatres. Acta Anaesthesiol Scand $1978 ; 22: 46-54$. 